\title{
Angiogenesis as a Therapeutic Target in Endometriosis
}

\author{
Angiogénese como um Alvo Terapêutico para a Endometriose
}

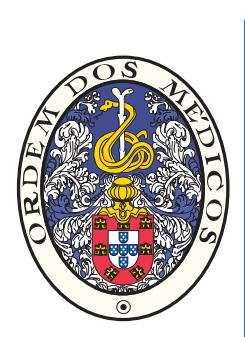

\author{
Dusan DJOKOVIC ${ }^{1,2}$, Carlos CALHAZ-JORGE ${ }^{1,3}$ \\ Acta Med Port 2014 Jul-Aug;27(4):489-497
}

ABSTRACT

Introduction: Angiogenesis is a key factor for the successful establishment and growth of endometriotic lesions.

Material and Methods: We performed a literature search in PubMed and reviewed the most pertinent studies published until January 2014 and focused on the endometriosis-associated angiogenesis and/or anti-angiogenic strategies for the treatment of this gynecological disorder.

Results: The present review provides a concise summary of the known molecular mechanisms that promote vascularization of endometriotic lesions and may serve as potential therapeutic targets. We also present a systematic overview of the inclusive and exclusive anti-angiogenic agents that have been already studied in cell cultures, animal models and/or endometriosis patients.

Discussion and Conclusion: The integration of anti-angiogenic approaches in the multimodal management strategies for endometriosis patients will be conditioned by the outcomes of future assessments regarding the effectiveness of such treatments, the risk of drug resistance development and the incidence of unacceptable side effects.

Keywords: Angiogenesis Inhibitors/therapeutic use; Endometriosis/drug therapy.

\section{RESUMO}

Introdução: A angiogénese é um factor determinante no estabelecimento e desenvolvimento das lesões de endometriose.

Material e Métodos: Foram revistos os artigos indexados na PubMed e incluídos os estudos mais relevantes, publicados até Janeiro de 2014, sobre a angiogénese nas lesões de endometriose e/ou estratégias anti-angiogénicas para o tratamento desta doença ginecológica.

Resultados: O presente artigo fornece um resumo conciso dos mecanismos moleculares conhecidos que promovem a vascularização das lesões de endometriose, podendo servir como alvos terapêuticos potenciais. Apresenta-se também uma revisão sistemática dos agentes anti-angiogénicos, inclusivos e exclusivos, que já foram avaliados em culturas de células, modelos animais e/ou doentes com endometriose.

Discussão e Conclusão: A integração das estratégias anti-angiogénicas na terapêutica multimodal de endometriose será condicionada pelos resultados de avaliações futuras da verdadeira eficácia desses tratamentos, do risco de desenvolvimento de resistência aos medicamentos e da incidência de efeitos colaterais inaceitáveis.

Palavras-chave: Inibidores da Angiogénese/uso terapêutico; Endometriose/terapêutica.

\section{INTRODUCTION}

Endometriosis is a common gynecological disorder characterized by vascularized growth of endometrium-like tissue outside the uterine cavity. The condition represents one of the most frequent causes of female infertility and chronic pelvic pain, resulting in highly elevated costs in terms of healthcare and loss of productivity. ${ }^{1}$ Currently available medical treatments are based on hormonal therapy that blocks ovarian function and provide transient effects, ${ }^{2}$ while surgical resection of the lesions is often necessarily extensive and associated with significant morbidity. ${ }^{3}$ Since the survival and proliferation of endometriotic implants require neovascularization, ${ }^{4}$ the inhibition of angiogenesis has become an attractive strategy for improved control of endometriosis.

\section{MATERIAL AND METHODS}

A literature search was performed in PubMed for the articles written in English language, published before
January 2014 and focused on the endometriosis-associated angiogenesis. Using the key words 'endometriosis' and 'endometriotic lesion', which were paired with the key words 'angiogenesis', 'vasculogenesis' and 'antiangiogenic drugs', we detected 394 articles. The most pertinent publications, i.e., the original studies focused on angiogenesis in endometriosis, performed in both preclinical models and humans, and previous reviews were included. Their citation lists were reviewed as well. Related book chapters, available to the authors, were consulted for a more comprehensive presentation of the information. Duplicate papers, letters to the editor and case reports we excluded. No institutional approval was required since only previously published data are presented.

\section{Neovascularization within endometriotic lesions}

The lesions of endometriosis typically possess dense vascular networks. Blood vessel proliferation is more

\footnotetext{
1. Departamento de Obstetrícia, Ginecologia e Medicina da Reprodução. Hospital de Santa Maria. Centro Hospitalar de Lisboa Norte. Lisboa. Portugal.

2. Instituto de Medicina Molecular. Faculdade de Medicina. Universidade de Lisboa. Lisboa. Portugal.

3. Clínica Universitária de Obstetrícia e Ginecologia. Faculdade de Medicina. Universidade de Lisboa. Lisboa. Portugal.

Recebido: 09 de Fevereiro de 2014 - Aceite: 30 de Abril de 2014| Copyright @ Ordem dos Médicos 2014
} 
prominent in the recto-vaginal implants (Fig. 1) than in the peritoneal lesions which vascularization is more exuberant than that of the ovarian endometriomas. ${ }^{5}$ It has been hypothesized that different processes, including retrograde menstruation, coelomic metaplasia, lymphogenic and hematogenic spread of endometrial cells as well as the recruitment and differentiation of bone marrow stem/ progenitor cells may lead to the endometriotic implant establishment. ${ }^{6}$ Regardless the exact mechanism(s) that give(s) origin to the endometriotic lesions, their survival is jeopardized by hypoxia, nutrient deprivation and waste metabolite accumulation. Thereby, a critical feature of endometriotic implants is the ability to become vascularized (Fig. 2).

At least four distinct mechanisms are considered to contribute to the vascularization of endometriotic lesions. They are: (I) sprouting of novel capillary blood vessels from the pre-existing vasculature, a process called angiogenesis; ${ }^{7-9}$ (II) splitting of a single pre-existing vessel in two new vascular segments through the insertion of a tissue pillar, i.e. vascular intussusceptions; ${ }^{10,11}$ (III) elongation/ widening of pre-existing vessels; ${ }^{12,13}$ and (IV) incorporation of circulating endothelial progenitor cells (EPCs) into vessels, a mechanism denominated vasculogenesis., ${ }^{914-16}$ Each mechanism includes different series of complexly regulated steps. For example, sprouting angiogenesis involves selective activation of endothelial cells (ECs), breakdown of the basement membrane, proliferation and organized migration of ECs, lumen formation, and stabilization of the endothelial tube by forming new basement membrane and mural cell coverage. ${ }^{17}$ Neovascularization is principally induced by hypoxia, as depicted in Fig. 2, while other triggers include tissue injury, inflammation and altered hormonal milieu in patients with endometriosis. ${ }^{6,12}$

\section{Molecular drivers of endometriosis-associated angiogenesis}

Angiogenesis is initiated when the dynamic balance

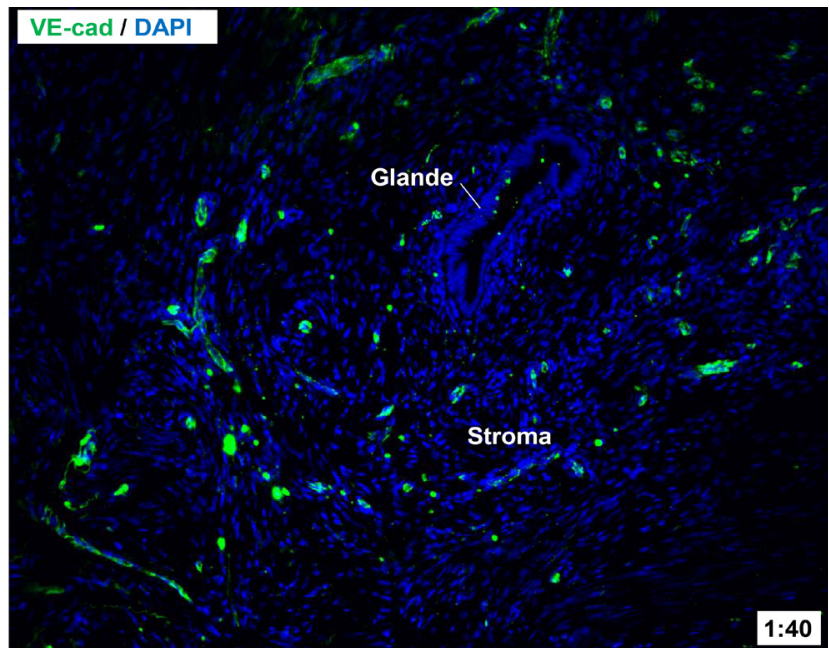

Figure 1 - Vascular network of a recto-vaginal endometriotic lesion. Blue, nuclear DAPI immunostaining; Green, VE-cad endothelial immunostaining between pro-angiogenic stimuli and anti-angiogenic factors is shifted in favor of vascular proliferation. Endometriotic implants, particularly early developing lesions, synthesize a range of pro-angiogenic proteins and express lower levels of angiogenesis inhibitors. ${ }^{4}$ In parallel, gene expression profiling of eutopic endometria from patients with endometriosis has shown up-regulation of multiple pro-angiogenic factors in comparison with endometria from healthy women. ${ }^{18-20}$ Peritoneal fluid from affected women exhibits elevated concentrations of diverse angiogenic growth factors and cytokines, and reduced amounts of antiangiogenic molecules. ${ }^{21-25}$

Equally as in physiological and tumor angiogenesis, vascular endothelial growth factor A (VEGF-A) plays the role of the principal positive angiogenic regulator in endometriotic lesions. VEGF-A specifically inhibits EC apoptosis ${ }^{26}$ and acts as a EC mitogen, ${ }^{27}$ enhances EC migration, ${ }^{28}$ and increases vascular permeability. ${ }^{29}$ VEGF-A and its principal receptor VEGF-R2 are strongly up-regulated in endometriotic lesions. ${ }^{20,30-32}$ Importantly, VEGF-A concentration in the peritoneal fluid significantly correlates with the stage of endometriosis. ${ }^{33}$

In addition to VEGF-A, important pro-angiogenic factors involved in endometriosis-associated angiogenesis are angiopoietins, Ang-1 and Ang-2. Although the expression of both factors is increased in endometriotic lesions, ${ }^{20,34}$ the shift of the Ang1/Ang2 balance in favor of Ang2 destabilizes pre-existing vessels and makes them prone to sprout. Furthermore, matrix metalloproteases favor angiogenic sprouting by cleaving the extra-cellular matrix, particularly MMP2, which production is stimulated by the activity of endometriotic cells in the peritoneal fluid. ${ }^{35}$ Platelet-derived growth factor B (PDGF-B) is regarded as the main promoter of the pericyte investment in neovessels, being significantly over-expressed by eutopic endometrium of endometriosis patients. ${ }^{4}$ Many other ubiquitously expressed molecules have been found to enhance angiogenesis in vitro, in animal models of endometriosis and/ or in human samples. ${ }^{12,36-40}$ Such promoters include cytokines and growth factors secreted by immune and neuroendocrine cells (e.g., interleukins, IL-1 $\beta, 6$ and 8 , tumor necrosis factor- $\alpha$, TNF- $\alpha$, and transforming growth factor $\beta$, TGF- $\beta$ ). Finally, not only the secreted factors but also several membranebound proteins, that mediate tumor angiogenesis, are likely engaged in the endometriotic neovascularization, such as DII4/Notch, vascular integrins and ephrins/Eph receptors. ${ }^{41-43}$

The effects of pro-angiogenic stimuli are antagonized by angiostatic factors, i.e. angiogenesis inhibitors that maintain vascular quiescence under physiological conditions. Endogenous angiogenesis inhibitors can be divided into two major groups: (1) extra-cellular matrix and basement membrane components, and (2) growth factors, cytokines and other non-matrix-derived proteins that directly repress ECs. ${ }^{17}$ Thrombospondin 1 (TSP1), a large multifunctional extra-cellular matrix glycoprotein, is a prototype of matrixrelated inhibitors, such as endostatin, while angiostatin, the 


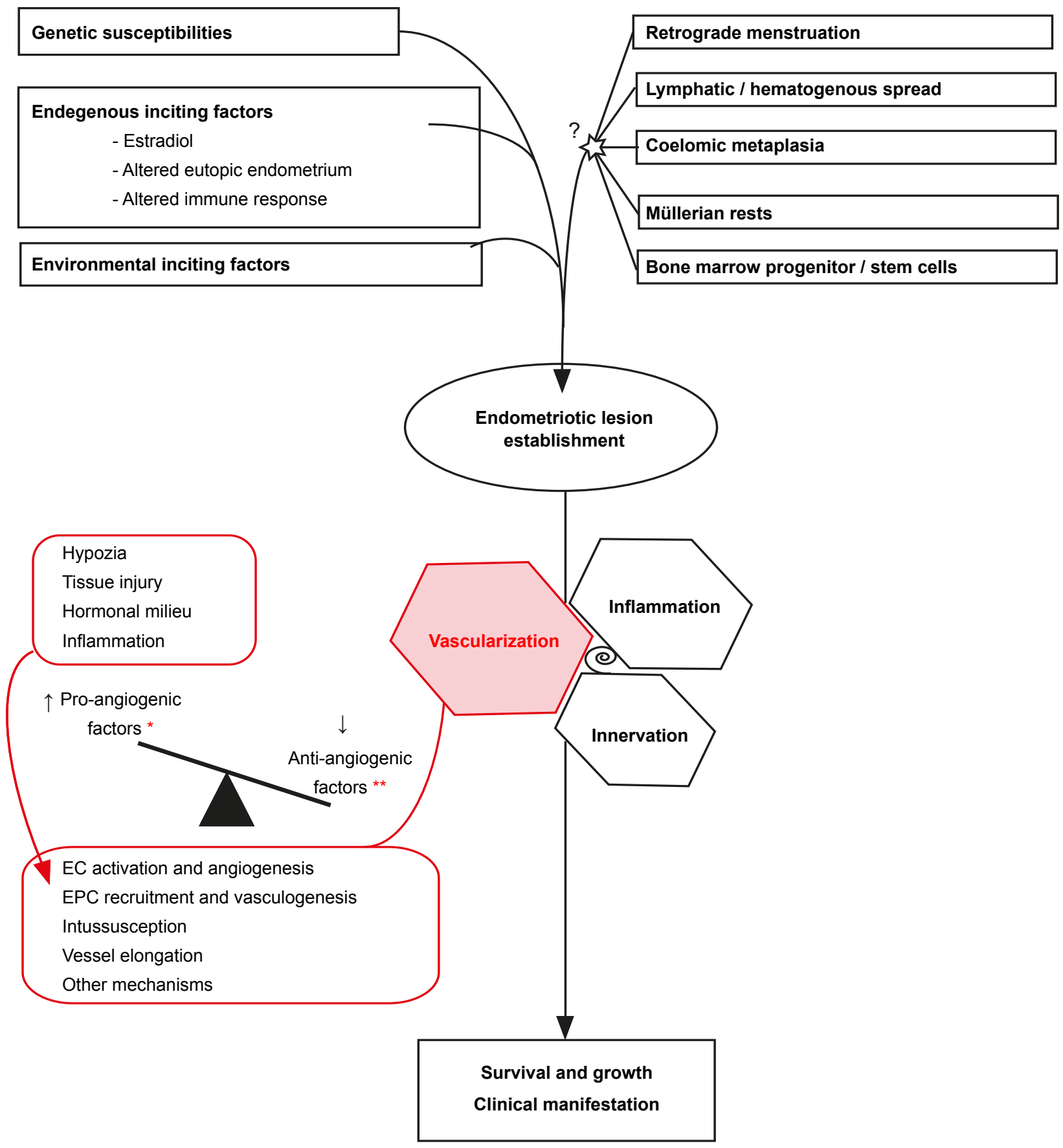

\section{* Pro-angiogenic factors}

\section{Soluble mediators}

(Angs, bFGF, HGF, IL1 $\beta, 6,8$, PDGF, TGF $\beta$, TNFa, VEGFA, etc.)

Membrane - bound molecules

(DII4/Notch?, Eph-4B/Ephrin-B2?, Integrins $\alpha 5 \beta 1, \alpha 5 \beta 3, \alpha 5 \beta 5)$

Mechanical forces - blood flow/shear stress

\section{** Anti-angiogenic factors}

Non-matrix-derived proteins

(e.g. angiostatin)

Matrix-derived proteins

(endostatin, thrombospondins, etc)

Figure 2 - Neovascularization in the pathogenesis of endometriosis. Angs, angiopoietins; $b F G F$, basic fibroblast growth factors; $H G F$, hepatocyte growth factor; $I L-1 \beta, 6,8$, interleukin $1 \beta, 6,8 ; P D G F$, platelet-derived growth factor; TGF- $\beta$, transforming growth factor $\beta$; $T N F-\alpha$, tumor necrosis factor $\alpha$;VEGF-A, vascular endothelial growth factor A; DII4, delta-like 4 receptor. 
plasminogen cleavage product, is a prominent non matrixderived angiogenesis inhibitor. ${ }^{44}$ These natural inhibitors of neovascularization modulate cell survival, proliferation, adhesion, and protease activation. ${ }^{44,45}$ Their proven downregulation or enhanced activity importantly influences angiogenesis and endometriotic lesion expansion. ${ }^{46-49}$ Thereby, endogenous angiogenesis inhibitors possess strong therapeutic potential.

Collectively, up-regulation of VEGF-A, secondary proangiogenic factors and mediators, and suppressed activity of angiogenesis inhibitors trigger the angiogenic switch. The growth and invasiveness of endometriotic lesion is absolutely dependent on the angiogenic switch, triggered and maintained neovascular proliferation. So, the rationale for considering anti-angiogenic strategies for endometriosis patients is based on this dependence. Promising drug candidates are likely to arise from further and more complete understanding of the molecular machinery governing endometriosis-associated angiogenesis.

\section{Therapeutic trials}

Development of appropriate bioassays made possible the discovery and assessment of the agents that target endometriosis-associated angiogenesis. ${ }^{50}$ These compounds can be classified as either exclusive antiangiogenic agents, which only one known function is the suppression of angiogenesis, or inclusive agents that have anti-angiogenic activity associated with other functions. ${ }^{17}$ The first group involves the blockers of pro-angiogenic signaling pathways, endogenous anti-angiogenic factors and their synthetic mimetics (Fig. 3). In contrast to anticancer drug development, the exclusive anti-angiogenic agents have not yet reached the clinical trials in patients with endometriosis. On the other hand, among 185 clinical trials on endometriosis registered within ClinicalTrials.gov on January 20, 2014, some have been assessing compounds previously demonstrated to act as inclusive anti-angiogenic agents (e.g. PPAR-y ligands).

Pro-angiogenic signaling blockers: Since VEGF-A is the key stimulus for endometriosis-associated angiogenesis, various VEGF-A signaling blockers have been initially evaluated in rodent models and/or chicken chorioallantoic membrane assay, including a soluble truncated VEGR-R $1^{51}$ and different anti-VEGF-A-antibodies. ${ }^{51-53}$ Indeed, these agents potently inhibited the establishment and growth of endometriotic lesions by disrupting their vascularization. Similar results were later obtained with VEGF-A-targeted gene therapy. ${ }^{54}$ Bevacizumab (Avastin ${ }^{\circledR}$, Genentech) - a humanized monoclonal IgG1 antibody that specifically inhibits all major isoforms of human VEGF-A - received US FDA approval in February 2004 for the use in 5-fluorouracilbased regimens for treatment of metastatic colorectal cancer. Few years later, Ricci and colleagues tested bevacizumab against surgically induced endometriotic lesions of BALB/c mice, and demonstrated that the experimental therapy significantly decreases VEGF-A peritoneal fluid level, cell proliferation within the lesions and their vascular density. ${ }^{55}$ However, serious toxicities (hemorrhage, proteinuria, severe hypertension, gastrointestinal perforation, poor wound healing, arterial thrombosis and reversible posterior leuko-encephalopathy syndrome) $;{ }^{17}$ will probably impede bevacizumab to be ever evaluated in women suffering from endometriosis. In addition, acquired drug resistance causes a serious concern due to redundancy of pro-angiogenic signals involved in the promotion of endometriosisassociated angiogenesis. This might be overcome by targeting multiple pro-angiogenic signaling pathways. For instance, Laschke and colleagues treated endometriotic lesions in a hamster model with two small molecule tyrosine kinase inhibitors, SU5416 and SU6668. ${ }^{56}$ While SU5416 only blocks VEGF-A receptors, SU6668 functions as a blocker of VEGF-A, basic fibroblast growth factor (bFGF) and platelet-derived growth factor B (PDGF-B) receptors. As expected, the simultaneous inhibition of three growth factors was significantly more efficient than blockade of VEGF-A signaling alone. Similarly, sorafenib (Nexavar®, Bayer/Onyx Pharmaceuticals), another multikinase inhibitor that interferes with VEGF-R2, VEGF-R3, B-Raf and other tyrosine kinase receptors, was highly efficient in a rat model of induced endometriosis. ${ }^{57}$ Despite the risk of cumulative toxicity that cannot be neglected, the concept of combined pathway targeting opens up perspectives for improved control of endometriosis.

\section{Endogenous and synthetic anti-angiogenic} compounds: Contrary to the agents that neutralize proangiogenic factor(s) or block its/their receptor(s) on ECs, endogenous and synthetic angiogenesis inhibitors directly target ECs and block the endothelium to response to proangiogenic factors. Thereby, they are commonly called direct anti-angiogenic agents. Acting on genetically stable ECs, they have been thought to be less prone to induce acquired drug resistance. ${ }^{17}$

Angiostatin and endostatin are endogenous antiangiogenic agents that have been already evaluated in endometriosis-bearing mice. Angiostatin was assessed in the form of gene therapy that, although effective, exerts strong side effects on the female reproductive organs. ${ }^{47}$ On the other hand, various independent studies in mice provide that endostatin and its functional synthetic fragments suppress angiogenesis and endometriosis without toxic effects, including the absence of any interference with the fertility and pregnancy development. ${ }^{48,49,53}$ Technical problems associated with the synthesis of the required amount of endostatin are probably the main reason that delays the drug progress towards clinical trials in women affected by endometriosis.

The first synthetic anti-angiogenic agent was TNP-470, an analogue of Aspergillus fumigatus antibiotic fumagillin. ${ }^{17}$ By decreasing microvessel density, TNP-470 potently impairs both tumor and endometriosis lesions in different models. ${ }^{53,58}$ However, it is an unsuitable drug candidate due to neurotoxicity and other unacceptable side effects. ${ }^{17}$ 
In contrast, TNP-470 derivative caplostatin was designed to have improved safety profile, being equally effective against endometriotic lesions in a rodent model. ${ }^{59}$ The main disadvantage of caplostatin is its poor oral availability and very short plasma half-life. More recently, lodamin was synthetized by conjugation of TNP-470 and an amphiphilic polymer. The initial assessment of lodamin in mice indicated that the treatment significantly decreases the level of circulating EPSs and the number of endometriotic lesions. ${ }^{15}$ This result is an additional indicator of the important role for vasculogenesis in the pathogenesis of endometriosis and supports the potential clinical use of non-toxic TNP-470 derivatives.

Inclusive anti-angiogenic agents: Anti-angiogenic activity was discovered as a secondary function of many drugs that had been previously approved for various diseases due to their distinct primary functions. In endometriosis models and/or patients, wide range of compounds, from hormones to anti-inflammatory and lipidlowering drugs have been found to interfere with both lesion growth and their neovascularization, as inclusive antiangiogenic agents (Fig. 3).

Suppressing the ovarian function, progestins, synthetic testosterone derivative danazol and gonadotropinreleasing hormone $(\mathrm{GnRH})$ agonists have been used in endometriosis patients for decades. There is evidence that these drugs possess anti-angiogenic activity as well. While estrogen increases VEGF-A expression, ${ }^{33}$ progesterone, dydrogesterone and dihydrodydrogesterone, ${ }^{60}$ such as danazol, ${ }^{61}$ reduce VEGF-A levels. Importantly, dienogest, an oral progestin, inhibited development and maturation of neovessels in a rat endometriosis model. ${ }^{62}$ In parallel, Khan and colleagues provided data showing that leuprolide acetate, a $\mathrm{GnRH}$ agonist, reduces macrophage infiltration and microvessel density in lesions collected from endometriosis patients. ${ }^{63}$ Thus, beneficial mechanisms of progestins, danazol and $\mathrm{GnRH}$ agonists encompass their angiostatic activity. As previously highlighted, favorable clinical outcomes are not long-lasting and the disease relapses with the cessation of the therapy.

In addition to the above mentioned drugs, dopamine agonists, such as ergot-derived cabergoline, used in gynecology and obstetrics for the treatment of hyperprolactinaemia and suppression of lactation, may cause the regression of endometriotic lesions by inhibiting mitosis and VEGF-A-mediated angiogenesis. ${ }^{64-66}$ Due to its quite favorable safety profile, non-ergot-derived dopamine agonist quinagolide was not only evidenced to be effective in pre-clinical trials, but also progressed to the clinical assessment. By suppressing VEGF-A signaling, proangiogenic cytokines and plasminogen activator inhibitor-1, the drug resulted in a $69.5 \%$ reduction of endometriotic lesions, while $35 \%$ of them completely vanished, in 9 women that required a surgical intervention and underwent a second-look laparoscopy. ${ }^{67}$ Dopamine agonists inhibit angiogenesis in an autocrine fashion by binding to the dopamine receptor D2 (DRD2) on endothelial cells that inactivates VEGFR2 ${ }^{68}$ Complementary, quinagolide binding to DRD2 on macrophages has been reported to decreases the expression of VEGF-A mRNA levels. ${ }^{69}$ Thus, it is likely that quinagolide also suppresses the endometriosisassociated angiogenesis in a paracrine fashion by decreasing the production of VEGF-A by immune cells within the lesions. ${ }^{70}$

Since endometriosis-associated inflammation and angiogenesis are closely related processes, numerous studies have been focused on anti-inflammatory drugs and immunomodulators. The principal enzyme in the conversion of arachidonic acid to prostaglandins, cyclo-oxygenase 2 (COX-2), is over-expressed in endometriotic lesions and eutopic endometrium of affected women, seeming to play multiple roles in the pathogenesis of endometriosis. ${ }^{71}$ Some COX-2 inhibitors suppress the endometriotic lesion growth, partially by the inhibition of angiogenesis. ${ }^{72}$ Such a compound is NS398. ${ }^{73}$ Although not all COX-2 inhibitors influence endometriotic lesions (e.g., nimesulid), ${ }^{51}$ selective inhibitors that do exert the effects appear as potential drug candidates, but significant cardiovascular side effects restrict their development.

Immunomodulatory agents with proven anti-VRGF-A anti-angiogenic effects on endometriotic lesions include lipoxin A4, rapamycin and pentoxifylline. ${ }^{74}$ The last one has been already assessed in patients with endometriosis. ${ }^{75}$

Nevertheless, there is still not enough evidence to support the use of pentoxifylline in women affected by endometriosis in terms of fertility promotion and symptoms relief.

Due to pleiotropic effects on energy metabolism, inflammation and angiogenesis, popularly denominated 'lipid-lowering drugs', both statins (simvastatin, atorvastatin, and lovastatin) and peroxisome proliferator-activated receptor (PPAR) ligands (fenofibrate, rosiglitazone, and pioglitazone) have been furthermore considered for potential inclusion in the multimodal management of endometriosis patients. ${ }^{74}$ Canadian study indicates that endometriosis patients may benefit from statins due to their inhibitory effect on angiogenesis. ${ }^{76,77}$ Similarly, inclusive anti-angiogenic PPAR-gamma ligands (rosiglitazone and pioglitazone) resulted in the regression of endometriotic implants in rodents, baboons and humans. ${ }^{74,78}$ Beside the efficacy, the risk for myopathies in the case of statins and cardiovascular lateral effects of PPAR-gamma ligands remain to be addressed in the future trials.

Finally, numerous pleiotropic phytochemical agents have been reported to exert anti-angiogenic effects and induce the regression of endometriotic lesions. ${ }^{74,79}$ The principal constituent of green tea, epigallocatechin-3-gallate, has been evidenced to block the VEGF-A expression of cultured hamster endometrial cells, inhibit angiogenesis in vivo and induce regression of endometriosis. ${ }^{80-82}$ Similar effects on the endometriotic lesions and their vessels have been observed in the experiments testing curcumin, a pharmacological active component of Curcuma longa. ${ }^{83}$ Puerarin (a compound isolated from Radix puerariae), 


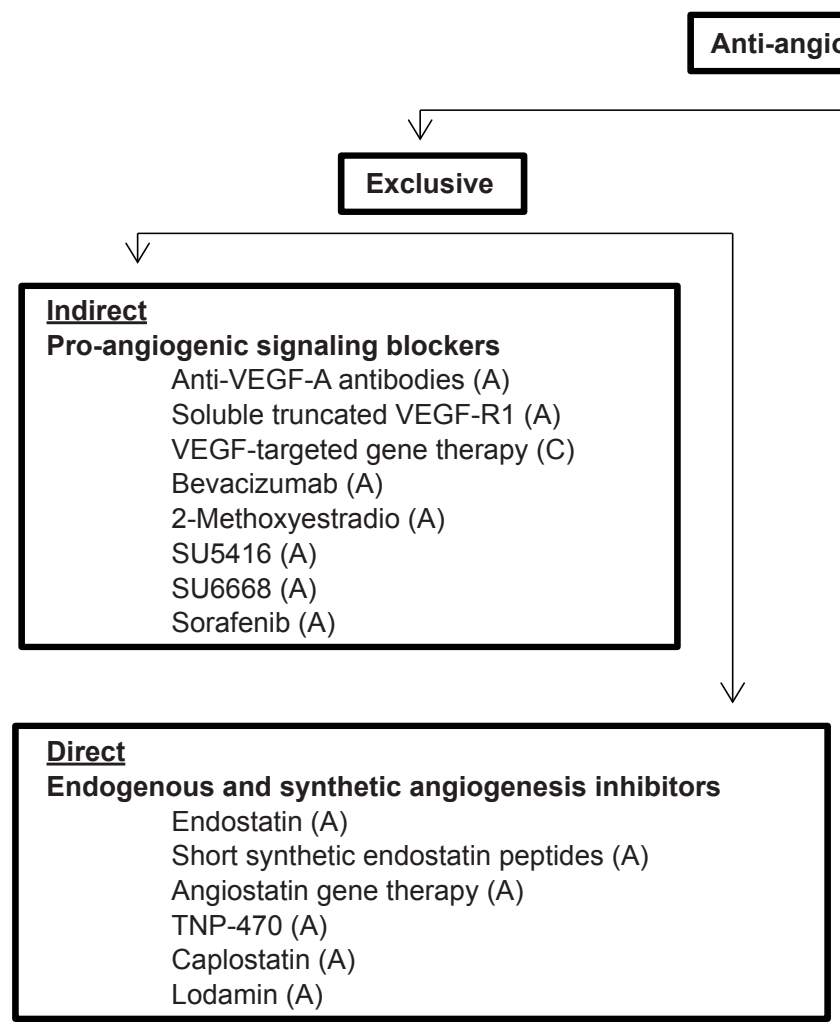

C - cell culture

A - animal model

$\mathrm{H}$ - trial in humans

$1^{\text {st }}$ COX-2 inhibitors

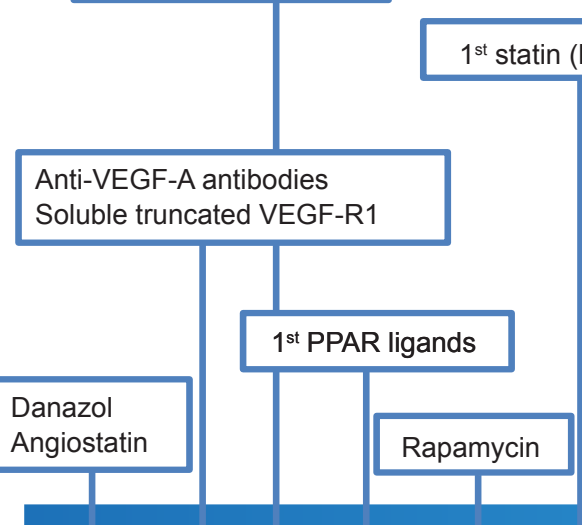

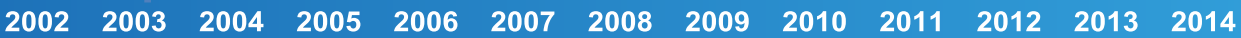

\section{Inclusive}

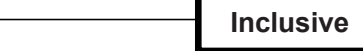

Hormones and functionally related substances

Progesterone $(\mathrm{A}, \mathrm{H})$

Dydrogesterone $(\mathrm{A})$

Dihydrodydrogesterone $(A)$

Dienogest $(A)$

Danazol $(\mathrm{A}, \mathrm{H})$

Leuprolide acetate $(A, H)$

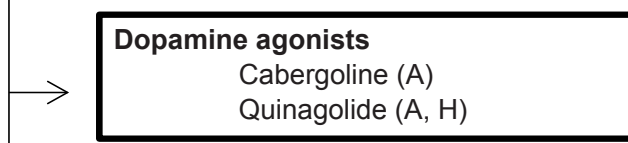

Anti-inflammatory drugs COX-2 inhitors

Rofecoxib (A)

Parecoxib (A)

Celecoxib (A)

NS398 (A)

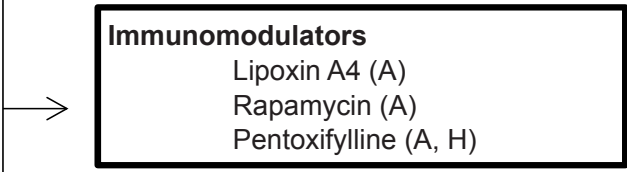

\begin{tabular}{|c|c|}
\hline Statins & $\begin{array}{l}\text { Simvastatin }(A) \\
\text { Atorvastatin }(C, A) \\
\text { Lavastatin }(C)\end{array}$ \\
\hline
\end{tabular}

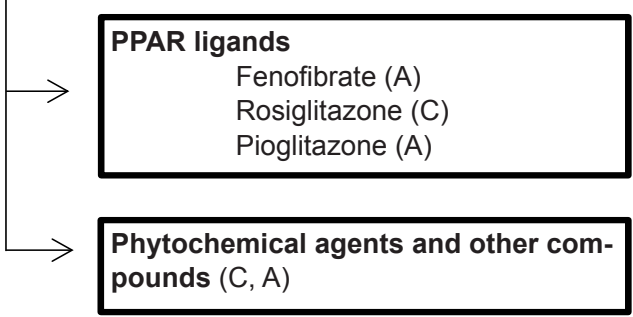

More than 40 different anti-amgiogenic candidates for endometriosis treatment assessed or currently under investigation

Figure 3 - Studied drug candidates with anti-angiogenic effects on endometriosis

4-hydroxybenzyl alcohol (a Gastrodia elata extract) and xanthohumol (a flavonoid purified from Humulus lupulus) have been additionally found to interfere with different steps of the angiogenic process and endometriotic lesion development. ${ }^{84-86}$ Nevertheless, there is a lack of functional pharmaceutical formulations and controlled clinical studies to support the consideration of medicinal herbs and synthetic phytochemical drugs in the treatment of endometriosis. 


\section{DISCUSSION AND CONCLUSION}

The validity of the concept of angiogenesis suppression in endometriosis patients has been supported by extensive research evidence. To assess the perspective of antiangiogenic therapy as a treatment for endometriosis, there are three major issues to be considered: the true effectiveness of the treatment, the risk of drug resistance development and the risk of unacceptable side effects.

In the first place, the existing information on the effectiveness of exclusive and most inclusive anti-angiogenic compounds has been obtained in animal models. It is questionable whether the specific mechanisms targeted in these experiments are the same as those that occur in humans where the lesions spontaneously develop and the disease has a chronic character. In accordance with the molecular analyzes of the human samples, the congruence exists in terms of involved signaling pathways, but it is likely that the most appropriate moment for anti-angiogenic treatment is already over when the symptomatic patients typically seek a medical assistance. While angiogenic vessels predominate in early endometriotic lesions, increased percentage of mature vessels characterizes the later stage lesions. ${ }^{87}$ Considering this fact, antiangiogenic drugs may effectively inhibit the newly forming lesions, but not later stage implants, particularly the rectovaginal lesions with abundant mature vessel networks. ${ }^{5}$ Angiogenesis targeting could be suitable for the prevention of recurrent endometriosis associated with currently used pharmacological and surgical treatment modalities. Further studies are required to define the patient profile(s) that will most benefit of anti-angiogenic therapy.

Besides, even if the angiogenesis is targeted in properly selected women (i.e., those with early primary or early relapsing disease), the experience from tumor patients indicates that the lesions may develop drug resistance. Specific suppression of an individual pro-angiogenic pathway will be certainly compensated by up-regulation of other angiogenesis promoters. The use of pleiotropic compounds and simultaneous targeting of different proangiogenic and other mechanisms importantly involved in the pathogenesis of endometrioses may provide improved and prolonged clinical benefit. Additionally, the application of anti-angiogenic compounds in combination with already approved drugs may be also appropriate. Such multimodal therapeutic regimens for endometriosis hypothetically require lower doses of each individual drug, resulting in both increased efficacy and reduced toxicity.

Finally, and of particular concern, are the lateral effects of angiogenesis inhibitors. Generally said, endometriosis is not a life-threatening disease, although malignant neoplasms rarely develop from endometriotic lesions. ${ }^{88}$ In parallel, most of the affected women are reproductive age individuals without significant comorbidities, desiring to preserve fertility or solve the problem of infertility. For this perspective, promising candidates are inclusive antiangiogenic agents with favorable safety profiles that have already received approvals for the treatment of benign disorders. Alternatively, in the absence of the evidence that endometriosis-specific angiogenic mechanisms exist and can be safely targeted, short-term anti-angiogenic regimens should be considered. Physiological angiogenesis is a fundamental prerequisite for normal reproductive function and embryonic/fetal development. Accordingly, a major challenge in the future research will be identification and validation of anti-angiogenic compounds that do not exert long-term effects on the vascular regeneration within ovaries, uterus and other healthy tissues.

Although a large number of anti-angiogenic agents have been demonstrated to be promising in preclinical studies, currently very few have been tested in humans such as quinagolide and pentoxifylline. Due to the time-consuming nature of the drug discovery and development process, no exclusive anti-angiogenic drug for endometriosis appears to be on the horizon. Industry-sponsored clinical trials that are based on a good risk/profitability balance are likely to access, in the first line, so called neoclassic compounds belonging to the group of inclusive anti-angiogenics (e.g., hormone-related substances, dopamine agonists, and PPAR ligands).

Understanding the pathophysiological mechanisms that promote angiogenesis within the endometriotic lesions is an essential prerequisite for the development of successful therapeutic strategies. Currently, there is a lack of clinical evidence for the efficacy and safety of anti-angiogenic treatments in endometriosis patients. Despite this fact, they hold promise to be effective against the newly forming lesions in the early stages of endometriosis and suitable for the prevention of the recurrent disease after surgery. Thus, a step forward in the care of endometriosis patient may result from targeted anti-angiogenic therapies.

\section{CONFLICTS OF INTEREST}

The authors declared no conflicts of interest.

\section{FUNDING SOURCES}

The authors declared no source of funding.

\section{REFERENCES}

1. Huntington A, Gilmour JA. A life shaped by pain: women and endometriosis. J Clin Nurs. 2005;14:1124-32.

2. Giudice LC, Kao LC. Endometriosis. Lancet. 2004;364:1789-99.

3. Dousset B, Leconte M, Borghese B, Millischer AE, Roseau G, Arkwright $\mathrm{S}$, et al. Complete surgery for low rectal endometriosis: long-term results of a 100-case prospective study. Ann Surg. 2010;251:887-95.

4. Hey-Cunningham AJ, Peters KM, Zevallos HB, Berbic M, Markham $\mathrm{R}$, Fraser IS. Angiogenesis, lymphangiogenesis and neurogenesis in endometriosis. Front Biosci. 2013;5:1033-56.

5. Itoga T, Matsumoto T, Takeuchi H, Yamasaki S, Sasahara N, Hosh $\mathrm{T}$, et al. Fibrosis and smooth muscle metaplasia in rectovaginal endometriosis. Pathol Int. 2003;53:371-5. 
6. Burney RO, Giudice LC. Pathogenesis and pathophysiology of endometriosis. Fertil Steril. 2012;98:511-9.

7. García Manero M, Olartecoechea B, Aubá M, Alcázar JL, López G. Angiogenesis y endometriosis. Rev Med Univ Navarra. 2009;53:8-13.

8. Jaffe RB. Importance of angiogenesis in reproductive physiology. Semin Perinatol. 2000;24:79-81.

9. Risau W. Mechanisms of angiogenesis. Nature. 1997;386:671-4.

10. Garcia-Velasco JA, Rizk B. Endometriosis: current management and future trends. New Delhi: Jaypee Brothers; 2010.

11. Burri PH, Tarek MR. A novel mechanism of capillary growth in the rat pulmonary microcirculation. Anat Rec. 1990;228:35-45.

12. Rocha AL, Reis FM, Taylor RN. Angiogenesis and endometriosis. Obstet Gynecol Int. 2013;2013:859619.

13. Gambino LS, Wreford NG, Bertram JF, Dockery P, Lederman F, Rogers PA. Angiogenesis occurs by vessel elongation in proliferative phase human endometrium. Hum Reprod. 2002;17:1199-206.

14. Laschke MW, Giebels C, Menger MD. Vasculogenesis: a new piece of the endometriosis puzzle. Hum Reprod Update. 2011;17:628-36.

15. Becker CM, Beaudry P, Funakoshi T, Benny O, Zaslavsky A, Zurakowski $D$, et al. Circulating endothelial progenitor cells are up-regulated in a mouse model of endometriosis. Am J Pathol. 2011;178:1782-91.

16. Asahara T, Murohara T, Sullivan A, Silver M, van der Zee R, Li T, et al. Isolation of putative progenitor endothelial cells for angiogenesis. Science. 1997;275:964-7

17. Figg WD, Folkman MJ. Angiogenesis: an integrative approach from science to medicine. New York: Springer; 2008.

18. Chung HW, Wen Y, Choi EA, Hao-Li, Moon HS, Yu HK, et al. Pleiotrophin (PTN) and midkine (MK) mRNA expression in eutopic and ectopic endometrium in advanced stage endometriosis. Mol Hum Reprod. 2002;8:350-5

19. Hur SE, Lee JY, Moon HS, Chung HW. Angiopoietin-1, angiopoietin-2 and Tie-2 expression in eutopic endometrium in advanced endometriosis. Mol Hum Reprod. 2006;12:421-6.

20. Di Carlo C, Bonifacio M, Tommaselli GA, Bifulco G, Guerra G, Nappi C Metalloproteinases, vascular endothelial growth factor, and angiopoietin 1 and 2 in eutopic and ectopic endometrium. Fertil Steril. 2009;91:231523

21. Cosín R, Gilabert-Estellés J, Ramón LA, Gómez-Lechón MJ, Gilabert $\mathrm{J}$, Chirivella M, et al. Influence of peritoneal fluid on the expression of angiogenic and proteolytic factors in cultures of endometrial cells from women with endometriosis. Hum Reprod. 2010;25:398-405.

22. Khoufache K, Bondza PK, Harir N, Daris M, Leboeuf M, Mailloux J, et al Soluble human IL-1 receptor type 2 inhibits ectopic endometrial tissue implantation and growth: identification of a novel potential target for endometriosis treatment. Am J Pathol. 2012;181:1197-205.

23. Laschke MW, Menger MD. In vitro and in vivo approaches to study angiogenesis in the pathophysiology and therapy of endometriosis. Hum Reprod Update. 2007;13:331-42.

24. Bersinger NA, Dechaud H, McKinnon B, Mueller MD. Analysis of cytokines in the peritoneal fluid of endometriosis patients as a function of the menstrual cycle stage using the Bio-Plex® platform. Arch Physiol Biochem. 2012;118:210-8.

25. Calhaz-Jorge C, Costa AP, Santos MC, Palma-Carlos ML. Peritoneal fluid concentrations of interleukin-8 in patients with endometriosis depend on the severity of the disorder and are higher in the luteal phase. Hum Reprod. 2003:18:593-7.

26. Gerber HP, McMurtrey A, Kowalski J, Yan M, Keyt BA, Dixit V, et al. Vascular endothelial growth factor regulates endothelial cell survival through the phosphatidylinositol 3'-kinase/Akt signal transduction pathway. Requirement for Flk-1/KDR activation. J Biol Chem. 1998;273:30336-43.

27. Connolly DT, Olander JV, Heuvelman D, Nelson R, Monsell R, Siegel N, et al. Human vascular permeability factor. Isolation from U937 cells. $J$ Biol Chem. 1989;264:20017-24

28. Dimmeler S, Dernbach E, Zeiher AM. Phosphorylation of the endothelial nitric oxide synthase at ser-1177 is required for VEGF-induced endothelial cell migration. FEBS Lett. 2000;477:258-62.

29. Lal BK, Varma S, Pappas PJ, Hobson RW, Durán WN. VEGF increases permeability of the endothelial cell monolayer by activation of PKB/akt, endothelial nitric-oxide synthase, and MAP kinase pathways. Microvasc Res. 2001;62:252-62.

30. Cho S, Choi YS, Jeon YE, Im KJ, Choi YM, Yim SY, et al. Expression of vascular endothelial growth factor (VEGF) and its soluble receptor-1 in endometriosis. Microvasc Res. 2012;83:237-42.

31. Donnez J, Smoes P, Gillerot S, Casanas-Roux F, Nisolle M. Vascular endothelial growth factor (VEGF) in endometriosis. Hum Reprod.
1998:13:1686-90.

32. Takehara M, Ueda M, Yamashita Y, Terai Y, Hung YC, Ueki M. Vascular endothelial growth factor $\mathrm{A}$ and $\mathrm{C}$ gene expression in endometriosis. Hum Pathol. 2004;35:1369-75.

33. Shifren JL, Tseng JF, Zaloudek CJ, Ryan IP, Meng YG, Ferrara N, et al. Ovarian steroid regulation of vascular endothelial growth factor in the human endometrium: implications for angiogenesis during the menstrual cycle and in the pathogenesis of endometriosis. J Clin Endocrinol Metab. 1996;81:3112-8.

34. Gescher DM, Berndorff U, Meyhoefer-Malik A, Moubayed P, Malik E. Immunolocalization of angiopoietin 1 in human peritoneal endometriotic lesions. Fertil Steril. 2004;81:S857-62.

35. Hassa H, Tanir HM, Tekin B, Kirilmaz SD, Sahin Mutlu F. Cytokine and immune cell levels in peritoneal fluid and peripheral blood of women with early - and late-staged endometriosis. Arch Gynecol Obstet. 2009;279:891-5.

36. Veillat V, Carli C, Metz CN, Al-Abed Y, Naccache PH, Akoum A Macrophage migration inhibitory factor elicits an angiogenic phenotype in human ectopic endometrial cells and triggers the production of major angiogenic factors via CD44, CD74, and MAPK signaling pathways. J Clin Endocrinol Metab. 2010;95:E403-12.

37. Maas JW, Calhaz-Jorge C, ter Riet G, Dunselman GA, de Goeij AF, Struijker-Boudier HA. Tumor necrosis factor-alpha but not interleukin-1 beta or interleukin- 8 concentrations correlate with angiogenic activity of peritoneal fluid from patients with minimal to mild endometriosis. Fertil Steril. 2001;75:180-5

38. McLaren J, Prentice A, Charnock-Jones DS, Millican SA, Müller $\mathrm{KH}$ Sharkey AM, et al. Vascular endothelial growth factor is produced by peritoneal fluid macrophages in endometriosis and is regulated by ovarian steroids. J Clin Invest. 1996;98:482-9.

39. Tariverdian N, Theoharides TC, Siedentopf F, Gutiérrez G, Jeschke $U$, Rabinovich GA, et al. Neuroendocrine-immune disequilibrium and endometriosis: an interdisciplinary approach. Semin Immunopathol. 2007;29:193-210

40. Rocha AL, Carrarelli P, Novembri R, de Pascalis F, Luisi S, Reis FM, et al. Activin A stimulates interleukin 8 and vascular endothelial growth factor release from cultured human endometrial stromal cells: possible implications for the pathogenesis of endometriosis. Reprod Sci. 2012;19:832-8.

41. Djokovic D, Trindade A, Gigante J, Badenes M, Silva L, Liu R, et al. Combination of Dll4/Notch and Ephrin-B2/EphB4 targeted therapy is highly effective in disrupting tumor angiogenesis. BMC Cancer. 2010;10:641.

42. Surrey ES, Lietz AK, Gustofson RL, Minjarez DA, Schoolcraft WB. Does endometrial integrin expression in endometriosis patients predict enhanced in vitro fertilization cycle outcomes after prolonged $\mathrm{GnRH}$ agonist therapy? Fertil Steril. 2010;93:646-51

43. Casals G, Ordi J, Creus M, Fábregues F, Carmona F, Casamitjana $R$, et al. Expression pattern of osteopontin and av $\beta 3$ integrin during the implantation window in infertile patients with early stages of endometriosis. Hum Reprod. 2012;27:805-13.

44. Ribatti D. Endogenous inhibitors of angiogenesis: a historical review. Leuk Res. 2009;33:638-44.

45. Dhanabal M, Sethuraman N. Endogenous angiogenesis inhibitors as therapeutic agents: historical perspective and future direction. Recent Pat Anticancer Drug Discov. 2006;1:223-36.

46. Tan XJ, Lang JH, Liu DY, Shen K, Leng JH, Zhu L. Expression of vascular endothelial growth factor and thrombospondin-1 mRNA in patients with endometriosis. Fertil Steril. 2002;78:148-53.

47. Dabrosin C, Gyorffy S, Margetts P, Ross C, Gauldie J. Therapeutic effect of angiostatin gene transfer in a murine model of endometriosis. Am J Pathol. 2002;161:909-18.

48. Becker CM, Sampson DA, Short SM, Javaherian K, Folkman J, D'Amato RJ. Short synthetic endostatin peptides inhibit endothelial migration in vitro and endometriosis in a mouse model. Fertil Steril. 2006:85:71-7.

49. Becker CM, Sampson DA, Rupnick MA, Rohan RM, Efstathiou JA, Short $\mathrm{SM}$, et al. Endostatin inhibits the growth of endometriotic lesions but does not affect fertility. Fertil Steril. 2005;84:S1144-55.

50. Edwards AK, Nakamura DS, Virani S, Wessels JM, Tayade C. Anima models for anti-angiogenic therapy in endometriosis. J Reprod Immunol. 2013;97:85-94.

51. Hull ML, Charnock-Jones DS, Chan CL, Bruner-Tran KL, Osteen $\mathrm{KG}$, Tom BD, et al. Antiangiogenic agents are effective inhibitors of endometriosis. J Clin Endocrinol Metab. 2003:88:2889-99.

52. Nap AW, Griffioen AW, Dunselman GA, Bouma-Ter Steege JC, Thijssen VL, Evers JL, et al. Antiangiogenesis therapy for endometriosis. J Clin 
Endocrinol Metab. 2004;89:1089-95

53. Nap AW, Dunselman GA, Griffioen AW, Mayo KH, Evers JL, Groothuis PG. Angiostatic agents prevent the development of endometriosislike lesions in the chicken chorioallantoic membrane. Fertil Steril. 2005;83:793-5.

54. Rein DT, Schmidt T, Bauerschmitz G, Hampl M, Beyer IM, Paupoo AA, et al. Treatment of endometriosis with a VEGF-targeted conditionally replicative adenovirus. Fertil Steril. 2010;93:2687-94.

55. Ricci AG, Olivares CN, Bilotas MA, Meresman GF, Barañao RI. Effect of vascular endothelial growth factor inhibition on endometrial implant development in a murine model of endometriosis. Reprod Sci. 2011;18:614-22.

56. Laschke MW, Elitzsch A, Vollmar B, Vajkoczy P, Menger MD. Combined inhibition of vascular endothelial growth factor (VEGF), fibroblast growth factor and platelet-derived growth factor, but not inhibition of VEGF alone, effectively suppresses angiogenesis and vessel maturation in endometriotic lesions. Hum Reprod. 2006;21:262-8.

57. Ozer H, Boztosun A, Açmaz G, Atilgan R, Akkar OB, Kosar MI. The efficacy of bevacizumab, sorafenib, and retinoic acid on rat endometriosis model. Reprod Sci. 2013;20:26-32.

58. Kruger EA, Figg WD. TNP-470: an angiogenesis inhibitor in clinical development for cancer. Expert Opin Investig Drugs. 2000;9:1383-96.

59. Becker CM, Wright RD, Satchi-Fainaro R, Funakoshi T, Folkman J, Kung $A L$, et al. A novel noninvasive model of endometriosis for monitoring the efficacy of antiangiogenic therapy. Am J Pathol. 2006;168:2074-84.

60. Mönckedieck V, Sannecke C, Husen B, Kumbartski M, Kimmig R, Tötsch $M$, et al. Progestins inhibit expression of MMPs and of angiogenic factors in human ectopic endometrial lesions in a mouse model. Mol Hum Reprod. 2009;15:633-43.

61. Matalliotakis IM, Goumenou AG, Koumantakis GE, Neonaki MA, Koumantakis EE, Dionyssopoulou E, et al. Serum concentrations of growth factors in women with and without endometriosis: the action of anti-endometriosis medicines. Int Immunopharmacol. 2003;3:81-9.

62. Katayama H, Katayama T, Uematsu K, Hiratsuka M, Kiyomura M, Shimizu $Y$, et al. Effect of dienogest administration on angiogenesis and hemodynamics in a rat endometrial autograft model. Hum Reprod. 2010;25:2851-8

63. Khan KN, Kitajima M, Hiraki K, Fujishita A, Sekine I, Ishimaru T, et al. Changes in tissue inflammation, angiogenesis and apoptosis in endometriosis, adenomyosis and uterine myoma after $\mathrm{GnRH}$ agonist therapy. Hum Reprod. 2010;25:642-53.

64. Novella-Maestre E, Carda C, Noguera I, Ruiz-Saurí A, García-Velasco JA, Simón $\mathrm{C}$, et al. Dopamine agonist administration causes a reduction in endometrial implants through modulation of angiogenesis in experimentally induced endometriosis. Hum Reprod. 2009;24:1025-35.

65. Novella-Maestre E, Carda C, Ruiz-Sauri A, Garcia-Velasco JA, Simon C, Pellicer A. Identification and quantification of dopamine receptor 2 in human eutopic and ectopic endometrium: a novel molecular target for endometriosis therapy. Biol Reprod. 2010;83:866-73.

66. Novella-Maestre E, Herraiz S, Vila-Vives JM, Carda C, Ruiz-Sauri A, Pellicer A. Effect of antiangiogenic treatment on peritoneal endometriosis-associated nerve fibers. Fertil Steril. 2012;98:1209-17.

67. Gómez R, Abad A, Delgado F, Tamarit S, Simón C, Pellicer A. Effects of hyperprolactinemia treatment with the dopamine agonist quinagolide on endometriotic lesions in patients with endometriosis-associated hyperprolactinemia. Fertil Steril. 2011;95:882-8.

68. Basu S, Nagy JA, Pal S, Vasile E, Eckelhoefer IA, Bliss VS, et al. The neurotransmitter dopamine inhibits angiogenesis induced by vascular permeability factor/vascular endothelial growth factor. Nat Med. 2001;7:569-74.

69. Chakroborty D, Chowdhury UR, Sarkar C, Baral R, Dasgupta PS, Basu S. Dopamine regulates endothelial progenitor cell mobilization from mouse bone marrow in tumor vascularization. J Clin Invest. 2008;118:1380-9.

70. Delgado-Rosas F, Gómez R, Ferrero H, Gaytan F, Garcia-Velasco J, Simón $\mathrm{C}$, et al. The effects of ergot and non-ergot-derived dopamine agonists in an experimental mouse model of endometriosis. Reproduction. 2011;142:745-55.

71. Cho S, Park SH, Choi YS, Seo SK, Kim HY, Park KH, et al. Expression of cyclooxygenase-2 in eutopic endometrium and ovarian endometriotic tissue in women with severe endometriosis. Gynecol Obstet Invest. 2010;69:93-100

72. Olivares C, Ricci A, Bilotas M, Barañao RI, Meresman G. The inhibitory effect of celecoxib and rosiglitazone on experimental endometriosis. Fertil Steril. 2011;96:428-33.

73. Laschke MW, Elitzsch A, Scheuer C, Vollmar B, Menger MD. Selective cyclo-oxygenase-2 inhibition induces regression of autologous endometrial grafts by down-regulation of vascular endothelial growth factor-mediated angiogenesis and stimulation of caspase-3-dependent apoptosis. Fertil Steril. 2007;87:163-71.

74. Laschke MW, Menger MD. Anti-angiogenic treatment strategies for the therapy of endometriosis. Hum Reprod Update. 2012;18:682-702.

75. Lu D, Song H, Li Y, Clarke J, Shi G. Pentoxifylline for endometriosis. Cochrane Database Syst Rev. 2012;1:CD007677.

76. Esfandiari N, Khazaei M, Ai J, Bielecki R, Gotlieb L, Ryan E, et al. Effect of a statin on an in vitro model of endometriosis. Fertil Steril. 2007:87:257-62.

77. Esfandiari N, Nazemian Z, Casper RF. Three-dimensional culture of endometrial cells: an in vitro model of endometriosis. Am J Reprod Immunol. 2008;60:283-9.

78. Guo SW. An overview of the current status of clinical trials on endometriosis: issues and concerns. Fertil Steril. 2014;101:183-90.

79. Jeong SJ, Koh W, Lee EO, Lee HJ, Bae H, Lü J, et al. Antiangiogenic phytochemicals and medicinal herbs. Phytother Res. 2011;25:1-10.

80. Laschke MW, Schwender C, Scheuer C, Vollmar B, Menger MD. Epigallocatechin-3-gallate inhibits estrogen-induced activation of endometrial cells in vitro and causes regression of endometriotic lesions in vivo. Hum Reprod. 2008;23:2308-18.

81. Xu H, Lui WT, Chu CY, Ng PS, Wang CC, Rogers MS. Anti-angiogenic effects of green tea catechin on an experimental endometriosis mouse model. Hum Reprod. 2009;24:608-18.

82. Xu H, Becker CM, Lui WT, Chu CY, Davis TN, Kung AL, et al. Green tea epigallocatechin-3-gallate inhibits angiogenesis and suppresses vascular endothelial growth factor $\mathrm{C} /$ vascular endothelial growth factor receptor 2 expression and signaling in experimental endometriosis in vivo. Fertil Steril. 2011;96:1021-8.

83. Zhang $\mathrm{Y}, \mathrm{Cao} \mathrm{H}, \mathrm{Hu} Y \mathrm{Y}$, Wang $\mathrm{H}$, Zhang $\mathrm{CJ}$. Inhibitory effect of curcumin on angiogenesis in ectopic endometrium of rats with experimental endometriosis. Int J Mol Med. 2011;27:87-94.

84. Wang D, Liu Y, Han J, Zai D, Ji M, Cheng W, et al. Puerarin suppresses invasion and vascularization of endometriosis tissue stimulated by 17ß-estradiol. PLoS One. 2011;6:e25011.

85. Laschke MW, Vorsterman van Oijen AE, Scheuer C, Menger MD. In vitro and in vivo evaluation of the anti-angiogenic actions of 4-hydroxybenzyl alcohol. Br J Pharmacol. 2011;163:835-44.

86. Rudzitis-Auth J, Körbel C, Scheuer C, Menger MD, Laschke MW. Xanthohumol inhibits growth and vascularization of developing endometriotic lesions. Hum Reprod. 2012;27:1735-44.

87. Van Langendonckt A, Donnez J, Defrère $S$, Dunselman GA, Groothuis $P G$. Antiangiogenic and vascular-disrupting agents in endometriosis: pitfalls and promises. Mol Hum Reprod. 2008;14:259-68.

88. Takeuchi M, Matsuzaki K, Uehara H, Nishitani H. Malignant transformation of pelvic endometriosis: MR imaging findings and pathologic correlation. Radiographics. 2006;26:407-17. 


\section{Angiogenesis as a Therapeutic Target in Endometriosis \\ Acta Med Port 2014:27:489-497}

Publicado pela Acta Médica Portuguesa, a Revista Científica da Ordem dos Médicos

Av. Almirante Gago Coutinho, 151

1749-084 Lisboa, Portugal.

Tel: +351218428215

E-mail: submissao@actamedicaportuguesa.com

www.actamedicaportuguesa.com

ISSN:0870-399X | e-ISSN: 1646-0758

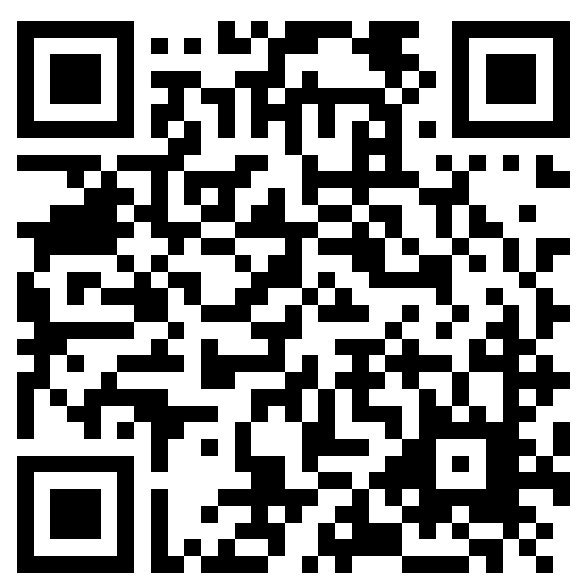

